\title{
Reflection of Social Exclusion in Documentary Film of Bangladesh: The Beauty Worker
}

\author{
Asrafi Bintay Akram*, Md. Faisal Haque, Md. Nawsher Oan and Hasan Jamil \\ Department of Social Science and Language, Hajee Mohammad Danesh Science and Technology University, \\ Dinajpur, Bangladesh
}

\begin{abstract}
This paper is about to explain how social exclusion is reflected in documentary film of Bangladesh. To fulfill the purpose of this study Neegar's documentary film The Beauty Worker has been selected. In the light of Gordon's theory of Exclusion, social exclusion has been analyzed through dialogues, actions and experiences of target group as documented in the selected movie. The approach used in this study is evaluative and descriptive. The paper employs qualitative method. The movie has been selected as a case study to explain data or information. The qualitative method has been employed based on secondary sources in this work to obtain an in-depth analysis of social exclusion in the context of Sociology and Sociology of Film.
\end{abstract}

Keywords: Reflection, social exclusion, documentary film beauty worker

\section{Introduction}

Since the dawn of the civilization millions of people have been driven from their homes and displaced within the border of their own countries for various natural and man-made disasters (Abrar and Lama, 2003). Over the last two decades, the number of such internally displaced persons $\left(\right.$ IDP $\left._{s}\right)$ has reached to over 25 million, dispersed in more than 40 countries. These are coerced or involuntary movements caused by development projects, armed conflicts, situation of generalized violence, violation of human rights and natural or human made disasters (Abrar and Lama, 2003). In fact, today there is no country of the world whose nationals have not migrated internally (rural to urban and urban to rural) and economical, geographical, social, demographic, political, religious, industrialization-all factors are liable for migration. When people are displaced from their settled society due to political, social and environmental causes etc. and at new areas most of the time they are stigmatized as parasites and eventually excluded spatially and socially. This situation is widely revealed in ethnic community. From one standpoint it is said that ethnic people of Bangladesh are treated as 'other or excluded' due to state polices since they do not belong to the dominant discourse of national identity. So, whenever this excluded community from the mainstream of society comes from their own society, they are being gradually displaced from their family and societal bond, to lose their own culture and heritage. In fact, they are unable to preserve their culture, language, customs, civil rights and so forth. Thus they are socially excluded forever .The crucial part of this study is that why the researchers have selected film especially documentary film as medium for understanding social exclusion.

Robert J. Brym (2006) has said-

- Why not hunt for sociological data in movies?

- Movies are as much a human product as newspaper are

- Because they are made by and about people in particular social and historical context.

- Movies can tell us a lot about typical patterns of inequality, ways of raising children, form of deviance, and just about all other aspects of social life.

- Movies are in many ways an ideal sociological data resource for research.

From the above mentioned points, it could be said very clearly that historical, social and political issues have to be identified for addressing the phenomenon 'social exclusion'and movie would be one of the best media for providing data. This is why according to the nature and subject matter the researchers have chosen film as a medium. In this study the researchers have selected a documentary entitled The Beauty Worker as a case study for explaining social exclusion. Actually few movies have been produced concerning political and environmental displacement. But The Beauty Worker is such a movie which has reflected social exclusion. The target people of this movie are ethnic women (Garo/Mandi-Banglaees call them 'Garo' but they call themselves 'Mandi-Human being'). Mandi women who came to Dhaka and started working in beauty parlors during the 70's are known as the beauty workers. They face the situations of social exclusion widely, but it remains veiled more. So, to analyze Reflection of Social Exclusion in Documentary Film of Bangladesh -the researchers have 
selected the movie The Beauty Worker as a case study which is related to ethnic community and social exclusion.

\section{Background}

In the 1936 British administrative reorganization of Mymensingh District which resulted with the emergence of a notion of a separate Garo homeland in Bengal. In 1964 there had been mass exodus of Garos across the international border into the Indian hills. This traumatic experience pushed the Garos to unify. In the Independence war of 1971 and the birth of Bangladesh all these three episodes (1936, 1964 and 1971) are directly related to state policies which excluded the Garos (as well as the neighboring minorities) from the dominant discourse of Bengali/Bangladeshi citizenship (Bal, 2007).

Amongst the Garos of Bangladesh they may broadly be distinguished four categories on the basis of habitat. The large majority reside in the most northern part that what used to be called Grater Mymensingh, bordering the Indian state of Meghalays. A second category (some, 15 percent) live in the Modhupur forest. A third segment are those who in the years after the partition of 1947 moved to the tea-estates and pan plantation in Sylhet (north-eastern Bangladesh, bordering the Khasi Hills in India). The fourth ever growing sub-section are those Garos who migrated to the larger towns and cities such Mymensingh, Dhaka and Chittagong (Bal, 2007). The main focus of this study on the last one category.

There had some factors (social \& political) which contributed to the process of identity formation or ethnicisation (Bal, 2000; cited by Bal, 2007) of Garos or Mandis. These were colonial discourse of tribe, administrative strategies to identity, categorization and governing the people of British India, the role of missionaries and religious conversion, the trans-national discourse and movement of indigenous people etc. It is remarkable that in Pakistan period Garos or Mandis were also excluded due to religious ideology. Because for last one and fifty years they have been practicing Christianity. In Pakistan, the notions of true citizenship were based on a shared Islamic identity that resulted in the (forceful) exclusion of the 'other (non-Muslim)' as outsiders (Bal, 2007).Unlike nearly 90 percent of the 150 million Bangladeshis who are Bengali Muslims, the Garos (and other so-called tribal communities) are neither Bengali by ethnicity and culture nor Muslim by religion( Schendel and Bal,2002).

So, it could be said that two discourses on national identity (based on an Islamic identity or on Bengali-ness) have continued to dominate the Bangladeshi national discourse. Hitherto no significant conceptions of Bangladesh as a multi-ethnic, multi-linguistic, multi religious nation-state have developed (Bal, 2007). Besides, in the EPZ (Export Processing Zone) area of Savar of the district of Dhaka, a large amount of Chakma, Marma and Tripura of CHT (Chittagong Hill Tracts) do work. Most of them have been rooted out from their own hill lands. Due to Military camps, possession by the settlers, commercial gardening in hill areas the indigenous people who are displaced from hill area are bound to become garments labor in Savar EPZ. Same incident has happened in the ground of Mandi and Coach communities of Madbupur Salban. Forest Department (FD), ADB (Asian Development Bank) and profit marketing of corporate agro business company extirpate local indigenous from their own land. Consequently, a large number of Mandi women are the workers of beauty parlors and garments industries in Dhaka city (Partho, 1414).

To recapitulate in short, in British, Pakistan and now in Bangladesh Garos or Mandis are deprived of space identity. They are spatially excluded in Bangladesh due to social and political causes of state and other agencies. Because they do not belong to the dominant discourse of certain period. So, they live in Bangladesh but they have no space identity and are considered 'others of Bangladesh' instead of Bangladeshi by nation. Eventually the Mandi women who came to Dhaka and started working in beauty parlors during the 70's are also spatially excluded, especially in jobs sectors due to territorial displacement within the social and political contexts.

\section{Method}

Data collection Method is the process by which information is gathered from respondents. According to the nature of this study there is no field work and naturally no information has been gathered from respondents. This study has been conducted based on secondary source (Selected documentary film) mainly.

This paper has been developed by linking two disciplines(Sociology and Film) up. So a sociological perspective is necessary to collect and analyze data as adopted from film.

The sociological perspective suggests at least FIVE criteria for evaluating movies, any one or more of which may be highlighted in a review They are-

1) How does the movie reflect its social context? 
2) How does the movie distort social reality?

3) To what degree does the movie shed light on common or universal social and human problems?

4) To what degree does the movie provide evidence for or against sociological theory and research?

5) To what degree does the movie connect biography, social structure and history? (Brym,2006)

The researchers have selected one among above mentioned criteria to collect data for analysis based on the nature and subject matter of this paper.

This is-

1.How does the movie reflect its social context, i.e. what can we learn about social condition in a particular time and place from the movie?

\section{Social exclusion : David Gordon and his colleagues}

Social exclusion was first introduced by sociological writers to refer to new sources of inequality. Social exclusion refers to the ways in which individuals may become cut off from full involvement in the wider society. (Giddens, 2006)

David Gordon and his colleagues mention four dimensions of social exclusion:

\section{Dimensions of social exclusion:}

(1) Poverty: Exclusion from adequate income or resources (Giddens, 2006).

(2) Labor market exclusion: Inactivity in labor market. Labor market exclusion can lead to the other forms of social exclusion-poverty, service exclusion and exclusion from social relations (Giddens, 2006).

(3) Service exclusion: An important aspect of social exclusion is lack of access to basic services. Service exclusion can involve individual exclusion (when an individual cannot use a service because they cannot afford to do so) or collective exclusion (when a service is unavailable to the community (Giddens, 2006).

(4) Exclusion from social relations: There are many ways in which people can be excluded from social relations.

First this type of exclusion can mean that individuals are unable to participate in common social activities, such as visiting friends and family, celebration of special occasion, spending time on hobbies, having friends round for a meal and taking holidays (Giddens, 2006). Second, people are excluded from social relations if they are isolated from friends and family (Giddens, 2006).

The researchers have discussed the social exclusion with reference to The Beauty Worker within the framework of exclusion as described by David Gordon and his colleagues.

\section{Gist of the selected movie: The Beauty Worker}

Dhaka, the people live here coming from different corners of the country. Dhaka also hosts different kind of business and livelihood for its habitants. Beauty parlor is one of the promising businesses these days in the city. Urban middle \& upper class women are the regular customers of these parlors. That is why beauty parlors are mushrooming on every corner of the city. For this reason, the owners of the parlors are always in search of employees. They prefer to employ ethnic women. It is very interesting that most of the beauty workers have come from ethnic community, both- hilly \& plain land and we call them 'adivasi'. The ethnic people are minority in Bangladesh. From early 80's the number of ethnic beauty workers has increased. These women come to Dhaka for survival. They come from villages. Most of them are illiterate. They get job for minimum salary with food and lodging. Their families depend on their income. It must be said that job opportunities are created by the beauty parlors for these women. They become economically self depended and empowered. Most of the beauty parlor owners are women. Even though the women workers here face much discrimination.

The characters in this documentary are a group of parlor workers. Their age range is between 15-20. They expressed their story of survival. The film basically focuses on their struggle in a cosmopolitan city- how do they cope with urban life leaving behind their own culture, their dreams and so on. (Souvenir, 2004-05: The contribution of women in national development, Produced by AV center, six documentaries directed by women, AV center, STD).

\section{Social exclusion and reflection in selected documentary film}

The film is made on the basis of interviews of the target group 'Mandi Women' who are parlor workers. Their interviews (dialogues), actions and experience are shared with the audiences through the reflection in this movie. In this movie it has been informed that in search of economic development Mandi women come to 
Dhaka city, i.e. they are displaced from their territory. After displacement, they struggle in a cosmopolitan city 'Dhaka' to cope with its urban life leaving behind their own culture, their dreams and so on. As a result they are excluded spatially and socially in terms of social exclusion which has been focused in this movie vividly.

\section{Spatial exclusion and its reflection in The Beauty Worker}

Mainly during the 70's a large number of Mandis came to Dhaka and started working in beauty parlors. Now more than one thousand Mandi girls are working in nearly two hundred and fifty parlors in Dhaka. The number is increasing day by day.

But why they have come to Dhaka. From this movie it has been informed that there are some social causes which lead them to leave their home forcefully as reflected through dialogues in this movie. Such as-

I came to Dhaka in 1983 to join in 'Hong Kong' a Chiness beauty parlor. There was no job in the village then (Selina Simsang, parlor worker).

or

In 1990 my parents arranged my marriage with my cousin. But I didn't like him. so, I came to Dhaka with my brother (Shapla Samsange, parlor worker).

or

........In fact if you have no education you can do this job (Poly Rema, parlor worker).

or

In fact hunger is terrible and.. you can't realize how tough it is, if you don't live in village. No scope to work. No food, let alone thrice meal a day. Not twice, not even once in a day they get food (Ranjit Ruga, coordinator, Nokmandi Garo Community Center).

or

.....they can't spend the money for education. Sometime they're in the same class far years... they leave and go to work in parlors (Shapla's sister, teacher at Mudhupur).

Hence, from above mentioned dialogues it could be said that for economic development they-women are moved away from their home. But there have been reasons behind this as well. Such as-

* Joblessness.

* Poverty, hunger etc.

* Lack of proper education.

* Since they belong to a matrilineal society, so they face lesser barriers in their society to enjoy freedom of mobility.

For these social causes when they leave their homes and try to cope with the urban life, here they are also spatially excluded. In the their job place, surrounding environments and urban life they feel alien and unwelcome and obviously, excluded. It has also been expressed in movie. For example-

... Some owner are very bad, treat us like their dogs (Lipa Chisim, parlor worker).

or

I know nothing about them. I feel curious after. But when I have the place, forget them (Laila Farzana, customer).

or

Bangalis disturb. They say "Look Chakma" (Tuli Chisim, parlor owner of Shahi Beauty Parlour).

or

Most of them are tribal (Kaniz Almas, parlor owner of Parsona Beauty parlor).

Through analyzing these experiences of Mandi women and the attitude of Bangalee as expressed in their words it could be said that-

* Since most of the owners of parlors are women but the women workers here face much discrimination.

* There has not been any social relation between workers and customers.

* Till now Bangalees do not take them as Bangalee/Bangladeshi. For this, our state policies, political ideology are liable. For belonging to the counter discourse of national identity they (Mandi) are treated as 'others'. Still now they are not recognized in our constitutions. 
Actually, for a long time Mandi women have been working at parlors. But they feel themselves alienated from their owners, customers, job place and even from their living place. Eventually, this spatial exclusion lead them to think of leaving this profession and backing to the village again.

\section{Social exclusion and its documentation in The Beauty Worker}

Four types of exclusion as described by David Gordon as focused in this movie as well.

* Poverty: For getting rid of poverty the Mandi women have come to the parlors of city to work. But are they free from poverty? Rather than, they are deeply involved in debt. Such as-

Ruga said in 'The Beauty Worker'-

"The owners give them huge amount of money as advance. They even get 50,000 to 1,00,000 tk. so they cannot leave the job without paying back the advance."

or

When the director said to George Risil (Selina's husband) that, Seli says when the loan is paid she will come back.

In reply, he said, she's (seli) telling that for last three or four years.

Actually in Dhaka city most of the parlors run based on the activism of Mandi women. Professionalism is deeply built in them. So, Bangalee owners do not leave them. To make them bound to work they give them huge loan in the name of welfare. It's a policy of modern capitalism.

* Labor market exclusion: Though it means inactivity in labor market, here it could be said in this context that the Mandi women are fixed themselves in this profession mainly.

During the seventies, they started coming to Dhaka. In the eighties many worked in garments, many in foreigner's houses. But in the nineties many started working in parlors mainly (Ranjit Ruga in 'The Beauty Worker').

Why the professional mobility has happened. Perhaps, sexual harassment is one of the causes which is reflected in this movie through Lipa's words-

".... there are people who engage girls in some bad works in the name of parlor's work."

So, physical security of these girls is a vital issue. Regarding this, Lipa also said.

"I like Dhaka........... but we, girls like us have no security here" ('The Beauty Worker')

* Service exclusion: The Mandi workers are also excluded from their basic service as documented in this film. For example:

... we worked hard but the food was not enough. Only boiled food. Some how we swallowed those (Lipa Chisim, parlor worker).

or

........ we did not get salary even on $17^{\text {th }}$ or $18^{\text {th }}$ of every month (Lipa).

or

Selis salary but that's not enough.......... (Seli's husband, though Seli is the senior most in this profession).

* Last but not least exclusion is 'exclusion from social exclusion' as portrayed vividly in this movie. For example

The director asked a question to a mother of parlor worker that they come to visit you. In reply she said, "Come once in a year. They don't get leave" ('The Beauty Worker').

Actually for the lack of leaves the Mandi women fail to meet their family, bond is going to be disjointed day by day. Similarly, they couldn't join their traditional festivals due to lack of cessation of labor. Such as-

Seli couldn't come to Wangale (traditional festive-the crops Mandi people ripen, they offer to the God first, and then they will eat). She didn't get leave (Selis husband).

Therefore, from the above mentioned discussion it could be said that for economic development the Mandi women are forced to displace themselves from their territory. These women come to Dhaka for survival. It must 
be said that job opportunities are created by the beauty parlors for these women. They become economically self dependant and also empowered. But simultaneously they are excluded spatially and socially as well.

\section{Argumentative discussion}

Here the movie has been discussed under the criterion as cited by Brym (2006), 'How does the movie reflect its social context?'

From the discussion as mentioned below, the similarities between the social context of the concerned issue of this study and its reflection in the movie The Beauty worker have been found.

With a few exceptions there are hardly any Banglee service providers in the beauty salons. The Mandi women simply dominate the parlors. Girls from other indigenous communities are yet to take up this profession (Parveen, 2008).According to Mandi community leaders there are several hundred salons across the country, majority of which are in Chittagong and Sylhet. However, there is no official statistics about the total number of such salons (Parveen, 2008).

To the Mandi girls who enjoy equal status with men in their matrilineal society working in a beauty salon is the highest achievement in life (Parveen, 2008). These Mandi workers had come from Madhupur forest, Haluaghat, Jhinaigati, Durgapur, Kalamnkanda, Nalitaboari and Muktagacha in Mymensing, Tangail, Sherpur and Netrakona districts. More than 100,000 Mandis live in these areas (Parveen, 2008). According to an estimation of Bangladesh Indigenous People's Forum, more than 50 percent of the Mandi beauty workers hail from Madhupur forest (Parveen, 2008).Due to counter discourses of national identity of Mandis in term of religion and space identity Mandis are excluded socially at their habitual areas. Such as majority of workers said that poverty was the main reason for their migration to the city. Most of these young women are the sole breadwinner of their family. They all start at there early teen, which also indicates a high dropout rate from the school. So, at Madhupur forest Mandi people were excluded from adequate resources or income. They had no labor market access, there collective exclusion of basic service (food, education) had happened.

Sanjeeb Drong, general secretary in Bangladesh Indigenous People's Forum, said Mandi community was very much attached to forest and nature but life became complicated for them for many reason (Parveen, 2008).Land was their main source of livelihood. Their forefathers used land for farming and did not know about property right. They did not know about paper worker due to lack of education. And this is how they lost it in Bangladesh.

Migration of Mandi women in large number started in the early 80's (Parveen, 2008). They became mostly garment workers. But soon they were replaced by Banglaee workers. Many chose the profession of nursing or domestic help at the house of the foreign diplomats. But at the same time they were increasingly hired by the beauty parlors, said Drong who also belongs to the Mandi community (Cited by Parveen, 2008). Social and political causes created the condition of territorial displacement of Mandi women. For economic development they came to Dhaka. But at new area they are also excluded once again. These young indigenous women however are allegedly subjected to many discriminations by a section of salon owners. Except for a few renowned salons, the situation is appalling in most of the parlors, Drong alleged (Cited by Parveen, 2008).

Working hours are very long. Often they are made to work without weekly holiday. Situation worsens during festival season. Many owners force the workers to reside inside the parlors to save house rent money. Trainee workers are often forced to do household work at the owner's house. Salaries are not paid regularly. For the lack of legal support for indigenous people these young women tend to stay quiet about their problems in most cases (Parveen, 2008). Although the Mandi women provide the service, they never set the trend and has very little chances of becoming their own masters. In Dhaka there is only one parlor named Shahi's in Mohammadpur that is owned by a Mandi woman. Nipa Shangma from Chapait, Madhupur, working at Persona said, 'Working at a parlor is a young Mandi woman's ultimate dream but there is no place to go from here as we don't have enough money to set up our own salons. So when they become older Mandi women always dream of buying land in the village' (Parveen, 2008).

So, it can be said that within the context of spatial and social space, identity, relationship, service Mandi women are not only excluded socially from Dhaka but also from Bangladesh. According to the suggestion of evaluating movies from sociological perspectives the selected movie The Beauty Worker has reflected this exclusion with social context. 


\section{Acknowledgement}

We owe special thanks to AV center of Steps Towards Development( a non government organization of Bangladesh) for providing us the selected documentary film.

\section{At a glance: The Beauty Worker \\ Documentary with English Subtitle}

Duration

Format

Video-grapy

Editing

Sound Recording

Associate researcher \& director

Script \& Director

Script \& Directional Advisor

Producer

Produced By

Year of Production

Copyright
: 32 minutes $21 \mathrm{sec}$

: Beta cam SP

: Sameera Haque

: Lutfun Nahar Mousumi

: Wahidur Rahman

: Farzana Boby

: Neegar

: Manzare Hassin

: Ranzan Karmaker

: Steps Towards Development

: 2004-2005

: Steps Towards Development

\section{References}

[1]. Abrar, Chowdhury R., Lama, Mahendra P. DISPLACED WITHIN HOMELANDS The IDPs of Bangladesh and the Region. Dhaka: Rmmru, 2003,1

[2]. Brym, J. Robert Sociology: Your Compass for a New World, Toronto: Nelson Education Limited, 2006

[3]. Bal, Ellen (2007) "Becoming the Garos of Bangladesh: Policies of Exclusion and the Ehtnicisation of a 'Tribal' Minority Journal of South Asian Studies, vol. xxx no3(2007): 439,444,454,455. http://www.escijournals.net/JSAS

[4]. Giddens, Anthony. 2006 Sociology (Fifth Edition), Cambridge: Polity Press. 2006.

[5]. Partho, Pavel. 'Garments Workers: Corporate Documentation of Agro life of Women and The Fun of Patriarchy (Bastrobalikara: Narir Khishijiboner Corporate Dolilayon o Parustrantik Moskora)' Bulletin of Film, No. 2 (March 1414- a Bengali year ), 9.

[6]. Parveen, Shahnaz (2008), 'Beauties at the city's beauty shops: Mandi girls are the main workforce of the beauty salons' The Daily Star [Online], October 13,2008.

[7]. Schendel, Cf. Willem van, and Bal, Ellen, 'Beyond the "Tribal" Mind-Set: studying Non-Bengali Peoples in Bangladesh and West Bengal', in Georg Pfeffer and Deepak Kumar Behera (eds), Contemporary Societies: Tribal Studies. Volume V: Concept of Tribal society (New Delhi: Concept Publishing Co., 2002

[8]. Souvenior 2004-05, The contribution of women in national development, produced by the AV center, 6 documentaries directed by the women, AV center, STD. 